\title{
Water, sanitation, hygiene and waste disposal practices as COVID-19 response strategy: insights from Bangladesh
}

\author{
S. M. Didar-UI Islam ${ }^{1}$ D . Prantor Kumar Mondal ${ }^{1} \cdot$ Nathanael Ojong $^{2}$. \\ Md. Bodrud-Doza ${ }^{3}$ - Md. Abu Bakar Siddique ${ }^{3}$. Moazzem Hossain ${ }^{4}$. \\ Mohammed A. Mamun ${ }^{5,6}$ (D)
}

Received: 22 July 2020 / Accepted: 9 December 2020 / Published online: 2 January 2021

(c) The Author(s), under exclusive licence to Springer Nature B.V. part of Springer Nature 2021

\begin{abstract}
The COVID-19 pandemic has caused a global emergence, and the absence of a proven vaccine or medicine has led to the implementation of measures to prevent and control the spread of the virus. Wearing protective equipment like mask and gloves, washing hands via soap, frequent use of antiseptic solution and maintaining social distance are being applied globally to reduce the transmission rate. Therefore, this study was intended to investigate water, sanitation and hygienic (WASH) behaviour, protective equipment use and their disposal practices among Bangladeshi residents amid the COVID-19 pandemic. Based on the study aims, data were collected mainly via an online survey and analysed through a set of statistical tools including $T$ test, one-way ANOVA and principal component analysis (PCA). This study found that almost $89.80 \%$ of the respondents reported to know about the COVID-19 and its preventive measures. WASH status of the respondents is found quite good, where $94.60 \%$ stated to have available potable water, $99 \%$ have improved toilet facilities, $95 \%$ wash their hands via soap, and $79.80 \%$ clean their house and toilets by antiseptic solutions properly. Moreover, nearly $94.50 \%$ and $54.80 \%$ people reported to use face mask and hand gloves, respectively, but the disposal practice of these protective equipment is inappropriate. More than $50 \%$ of people reported disposing of their used mask, gloves and tissue with other household wastes, which is alarming for public health and environmental perspective. Moreover, the WASH and waste disposal practices of the marginal people were found very poor and not at a satisfactory level. The results of statistical analysis focused on WASH and waste disposal practices as well as the factors which influence these practices. It is found that gender, occupation, area of residence, and level of education of the participants mainly influence the WASH and waste disposal practices. It is expected that this study exposed the necessity to introduce proper infectious waste management policy and also the increase in awareness level among mass people regarding the preventive measures of COVID-19 infection to combat against disease transmission and environmental pollution.
\end{abstract}

Keywords COVID-19 pandemic · Water sanitation hygiene (WASH) · Waste disposal · Public health $\cdot$ Environmental pollution

Supplementary Information The online version of this article (https://doi.org/10.1007/s10668-02001151-9) contains supplementary material, which is available to authorized users.

S. M. Didar-U1 Islam

didar_577@yahoo.com

Extended author information available on the last page of the article 


\section{Introduction}

The coronavirus disease 2019 (COVID-19) outbreak was initially identified in Wuhan City of Hubei province in China, and was declared as a pandemic by the World Health Organization (WHO) on March 11, 2020, 3 months after first appeared because of its rapid transmission rate and threat to public health (Ojong 2020; WHO 2020a). The surge of COVID-19 reached every continent of the world and claimed to spread 218 countries, areas or territories with the death of 11,55,553 humans from 4,31,47,494 confirmed cases till 27th October of 2020 (WHO 2020b). Coronaviruses are pathogens that primarily target the respiratory system in humans (Rothan and Byrareddy 2020). The most common symptoms at the onset of COVID-19 are fever, cough, sore throat, and fatigue, while other symptoms include headache, sputum production, hemoptysis, dyspnoea, diarrhoea, and lymphopenia (Huang et al. 2020; Mamun and Griffiths 2020). Severe COVID-19 cases can lead to cardiac injury, respiratory failure, acute respiratory distress syndrome, and even death (Holshue 2020; Islam et al. 2020a). Although the virus can infect people of all ages, evidence to date suggests that older people and those with underlying medical conditions are at a higher risk of getting severe COVID-19 disease (Das et al. 2020a). COVID-19 is currently being transmitted by human-to-human contact or via contact routes (Chen et al. 2020; Ilesanmi and Afolabi 2020). Human-to-human transmission occurs primarily through direct contact or through droplets spread from an infected person (Delgado et al. 2020; Kour et al. 2020). Contact transmission occurs when people with contaminated hands touch their nose, eyes, or mouth (Mushi and Shao 2020), while indirect contact transmission may happen when the virus is transferred from one surface to another by contaminated hands (Anderson et al. 2020).

To date, there is no effective medicine or vaccine developed, combating the disease and limiting its spread is the key concern. Hence, national and international authorities and experts suggest to take non-pharmaceutical preventive measures like washing hands via soap, frequent use of antiseptic solution, wearing personal protective equipment (e.g., face masks, hand gloves etc.), and maintaining social distance (Cook 2020; Qian and Jiang 2020; Sajed and Amgain 2020; WHO 2020c). Washing hands with soap and use of protective equipment (e.g., wearing a mask) as a means of preventing and controlling infectious diseases that has the advantages of simple operation, low cost and highly effective against the virus transmission (Labrague et al. 2018; Brauer et al. 2020), which proved to be effective during the outbreak of severe acute respiratory syndrome (SARS) (Jefferson et al. 2009). Access to safely managed water, sanitation and hygiene (WASH) serve as barriers to human-to-human transmission of COVID-19 (Das et al. 2020b). The question of handwashing is particularly important in low-income countries where over half of the population do not have access to a handwashing station in the home (Ray 2020). Lack of water and sanitation compromise efforts for hygiene (Corburn et al. 2020), which in turn impacts prevention and control of COVID-19 spread in communities. Luby et al. (2005) reported that frequent handwashing can reduce the risk of viral transmission by 55\%. Handwashing with water and soap has been proven to reduce transmission and disease risk, especially in times of disease outbreaks (Yates et al. 2017; Brauer et al. 2020; Ray 2020). WASH interventions can also be used to control the spread and transmission of disease in treatment facilities (Yates et al. 2017). Inadequate WASH services can increase the risk of COVID-19 spread, along with other diseases such as diarrhoea, cholera, typhoid, and hepatitis (Islam 2013; Hathi et al. 2017; Das et al. 2020b). Despite the importance of adequate WASH practices, protective equipment use and proper waste disposal are important concerns. WASH interventions 
could also include waste disposal (Yates et al. 2017). WHO (2020d) stated that good WASH along with proper waste disposal practices can help to prevent the COVID-19 transmission at the community level. It is reported that the amount of household and infectious medical wastes is increased in many countries including Bangladesh during the pandemic (Rume and Islam 2020; Rahman et al. 2020). The increased use of protective equipment and their haphazard disposal creates environmental threats (Fadare and Okoffo 2020; Islam et al. 2020b; Rume and Islam 2020) and enhances the risk of disease transmission to waste workers as well as community level (Ma et al. 2020; Singh et al. 2020).

Clearly, WASH and waste disposal practices have a crucial role to play in preventing and controlling the COVID-19 spread; however, the question regarding WASH and waste disposal practices of the population in everyday life has been a relative blind spot within the existing literature on COVID-19. This paper attempts to fill this gap by examining the WASH and waste disposal practices of the population in Bangladesh as well as the factors which influence these practices. The paper makes two key contributions. First it contributes to the emerging literature on WASH and COVID-19 by providing empirical work on WASH and waste disposal practices of the population in Bangladesh. Second, from a policy perspective, this study would enable the government of Bangladesh to identify gaps in its outbreak mitigation strategies that aim to prevent and control the spread of COVID-19. For instance, regarding COVID-19 information, the government may consider using multiple channels in order to get vital information to various segments of the population. As there is no prior study, hence it is expected that this study will expose the existent scenario of the WASH status along with safety equipment's use and their disposal practices amid COVID19 in Bangladesh, which might be helpful for the local administrations and policymakers.

To delineate the study protocols and findings, the rest part of the paper is organised as follows: research methodology with the encompasses of context of the study, data collection, analysis, and limitations, and then we present and discuss the results (specifically demographic profile of the participants, and subsequently focus on their WASH and waste disposal practices, including the factors which influence these practices, and environmental and health effects of inadequate WASH and waste disposal), and finally, we provide concluding remarks and make policy recommendations.

\section{Methods}

\subsection{Context}

The study was conducted in Bangladesh, a country with 164 million inhabitants. Dhaka, the country's capital and one of the world's top ten megacities, is host to 18 million inhabitants, and this figure is projected to reach 28 million by 2030 (UNDESA 2018). The city's population density is 11,910 per $\mathrm{km}^{2}$, and the figures are higher in the core region of the city (Corner and Dewan 2014). Accompanying the growth in the urban population is the growth of populations in slums, and the United Nations estimates that 10 million people in Bangladesh live in slums (UNDP 2020). Since 1990, the country's population has experienced a $20 \%$ gain in water access and $29 \%$ gain in sanitation access (World Bank 2018). Based on estimates, $87 \%$ of the population drinks from an improved water source, and about $63 \%$ uses improved sanitation facilities. Although there has been significant improvement with respect to access to improved water sources, most of the population currently live in environments plagued by inadequate WASH, which leads to negative health 
outcomes, and the country records over 76 million diarrhoea episodes each year (Zohura et al. 2020). Moreover, waste disposal and management system of the country is not adequate enough. Due to lack of proper monitoring, wastewater discharged from municipal and industrial sources is drained into nearby water bodies (Islam and Azam 2015; Islam and Huda 2016; Rahman and Islam 2016).

However, like other countries, the country has been severely affected by COVID-19. The country recorded its first confirmed case on March 8, 2020 (Anwar et al. 2020). The infection rate being slow in the beginning saw a steep rise in April and has continued increasing later on and infected the entire country. As of October 27, 2020, a total of 4,00,251 confirmed cases besides 3,17,000 recovered and 5818 deaths are reported in the country (IEDCR 2020). It is also reported that $26.7 \%$ of the confirmed cases were within the range of age group $31-40$ years, $20 \%$ in the $21-30$ years, $18.8 \%$ in the 41-50 years, $15.2 \%$ among people aged $51-60$ years, $11 \%$ above 60 years and $8.3 \%$ below 20 years (WHO 2020e). The COVID-19 situation including confirmed cases, death, recovery and the geographical distribution are present in Fig. 1. To prevent the spread of the virus, the country has witnessed a lockdown since March 26, 2020, in the form of general holidays except emergency services (Islam et al. 2020a). But, for the sake of the country's economy, the government eased a more than two-month lockdown
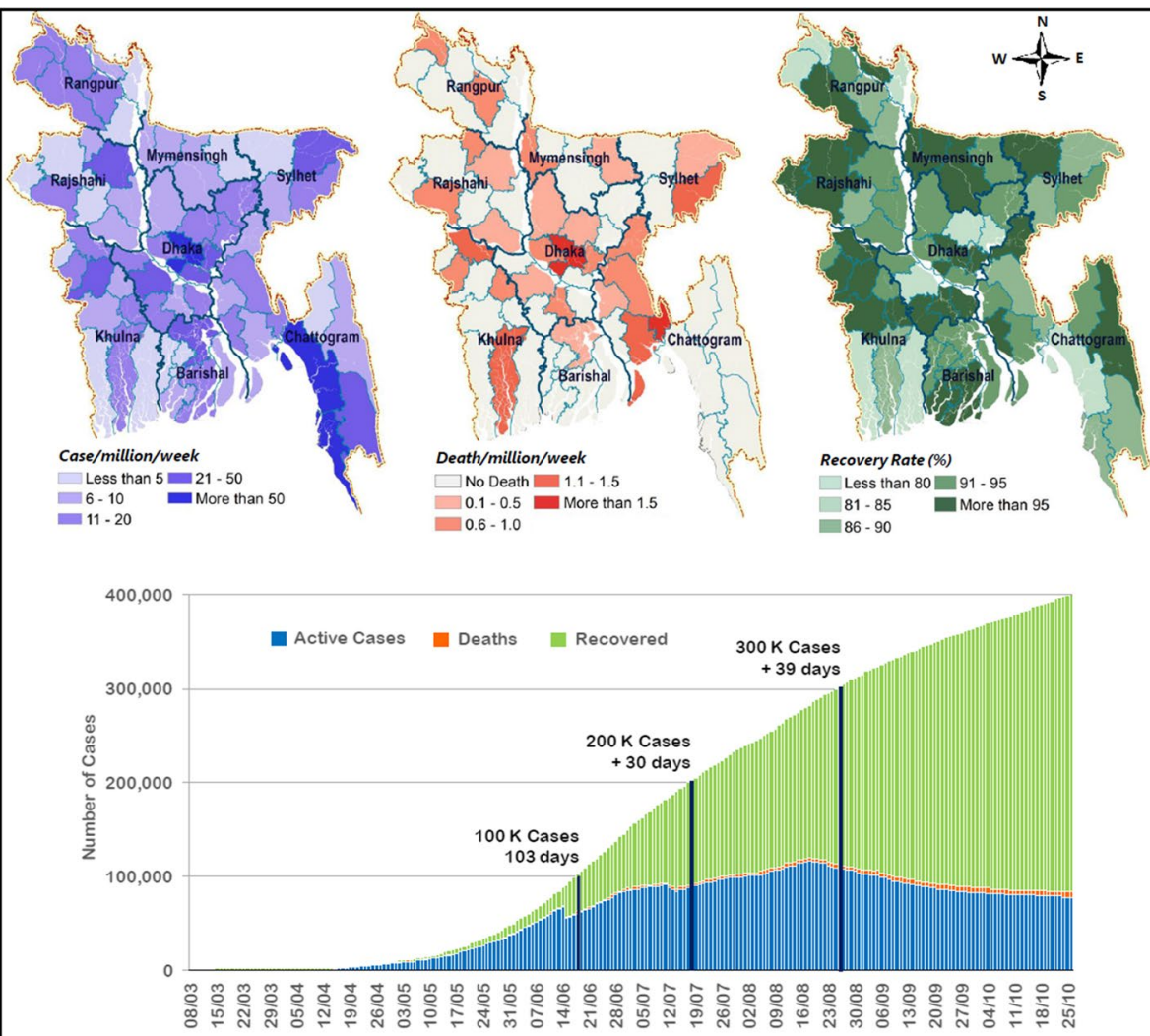

Fig. 1 Figure showing the weekly confirmed cases of COVID-19, death, and recovered in Bangladesh along with geographical distribution as of 25 October 2020 ( Source: WHO 2020e) 
after 31 May 2020, though educational institutions are closed yet (Kamruzzaman 2020). Government encouraging people to stay at home, not to go outside without an emergency, to avoid crowd places, maintain social distance, use personal protective equipment, and maintain personal hygiene to prevent human-to-human virus transmission (DGHS 2020). But, due to socioeconomic condition, population density, illiteracy and weak governance, these measures face challenges in Bangladesh (Bodrud-Doza et al. 2020b; Shammi et al. 2020).

\subsection{Data collection procedure}

To explore the present study aims, a self-developed questionnaire was applied in consideration of the country's socio-economic condition, national and international guidelines and literatures. The questionnaire encompassed demographics characteristics (e.g., age, gender, occupation, geographic locations, and level of education), WASH status (e.g., availability of water, and their sources, handwashing practice, cleaning and disinfection of house and toilets, wash clothes and wears after returning from outside etc.), protective equipment's use and their disposal issues (e.g., wearing mask, hand gloves and re-use issue, disposal practices etc.), and awareness related questions (e.g., awareness of preventive measures of COVID-19, sources of information etc.). Along with multiple choice option, a five-point (1-5) Likert scale was used for testing the statement descriptions that ranged from strongly disagree to strongly agree with the statements (Table 2).

An online survey was conducted from 20 May to 19 June 2020 among the Bangladeshi adult (>18 years) residents. Research participants were contacted via email and social platforms (e.g., Facebook, Messenger, and WhatsApp), and shared an introductory paragraph describing the objective of the study and basic terminology of the studied terms, as well as ethical issues. As a result of the ongoing pandemic, the study adopted a convenience sampling technique, meaning that the survey was completed by people who were available and willing to take part in the study. The survey link was sent to those who agreed to take part in the study. A total of 1303 research participants completed the survey, which was used for further analysis. In addition, to understand the WASH and waste disposal behaviour of marginal people (usually poor, illiterate/no formal education/less educated, live in a poor area or slum, no smartphone or device, and internet facility) who we couldn't reach via online, an informal face-to-face interview was administered to 50 people. Thus, in total, 1353 participants took part in the study.

\subsection{Data analysis}

Data were analysed using a set of statistical tools i.e., frequency, percentage, $T$ test, oneway ANOVA, and principal component analysis (PCA) with the Microsoft Excel (2010) and Statistical Package for Social Sciences (SPSS) version 25.0. $T$ test and one-way ANOVA were performed to determine the relation among the studied variables with the respondent's demographic characteristics. Generally, the $T$ test is performed to determine whether there is any statistically significant difference between the means of two groups, while the one-way ANOVA is used to determine whether there are any statistically significant differences between the means of three or more independent groups (Howell 2002; Kim 2015). Furthermore, PCA is a data reduction tool that demonstrates each potentiality of the parameters and their confidence level in large sample datasets (Bodrud-Doza 
Table 1 Demographic information of the respondents attended in online survey

\begin{tabular}{|c|c|c|c|}
\hline Socio-demographics variables & Group/Classification & $\begin{array}{l}\text { Frequency } \\
(n=1303)\end{array}$ & Percent $(\%)$ \\
\hline \multirow[t]{2}{*}{ Gender } & Male & 745 & 57.20 \\
\hline & Female & 558 & 42.80 \\
\hline \multirow[t]{5}{*}{ Age } & $18-30$ years & 995 & 76.34 \\
\hline & $31-40$ years & 191 & 14.67 \\
\hline & $41-50$ years & 83 & 6.39 \\
\hline & $51-60$ years & 23 & 1.76 \\
\hline & $>60$ years & 11 & 0.84 \\
\hline \multirow[t]{2}{*}{ Area of residence } & Rural & 365 & 28.0 \\
\hline & Urban & 937 & 72.0 \\
\hline \multirow[t]{7}{*}{ Level of education } & Primary & 17 & 1.30 \\
\hline & Secondary & 50 & 3.83 \\
\hline & Higher secondary & 318 & 24.40 \\
\hline & Graduate & 632 & 48.52 \\
\hline & Post graduate & 253 & 19.41 \\
\hline & $\mathrm{PhD}$ & 9 & 0.70 \\
\hline & No formal education & 24 & 1.84 \\
\hline \multirow[t]{7}{*}{ Occupation } & Business & 30 & 2.30 \\
\hline & Service & 219 & 16.80 \\
\hline & Student & 833 & 63.90 \\
\hline & Teacher & 42 & 3.22 \\
\hline & Housewife & 48 & 3.68 \\
\hline & Unemployed & 73 & 5.60 \\
\hline & Others & 58 & 4.50 \\
\hline
\end{tabular}

et al.2020a). PCA was performed using Varimax rotation with Kaiser Normalization, in order to maximize the sum of the variance of the factor coefficients (Bodrud-Doza et al. 2019b), which better explains the studied factors. Before conducting the PCA, KaiserMaier-Olkin (KMO) and Bartlett's sphericity tests were used to confirm the necessity of this analysis. The results of the KMO test (that is, 0.832) and Bartlett's sphericity test (that is, $p<0.01$ ) suggest that our datasets are fit for PCA (Bodrud-Doza et al. 2020b; Islam et al. 2002a; Shammi et al. 2020). The number of factors chosen was based on Kaiser's principle; that is, only factors with eigenvalues $>1.0$ were considered. A detail flowchart describing the research methodology is presented in Fig. 2.

\subsection{Limitations}

This study presents some limitations that should be considered when reading the findings. As mentioned earlier, as a result of the current pandemic, random sampling could not be used to recruit research participants. In compliance with the ethical protocol, the study relied on people who were in a state to take part in the study. It is also because of the current pandemic, the survey was conducted via online, although an effort was made to administer a face-to-face interview to people with no access to internet or smart phone, the total number of people in this category is minimal, and not followed the structured 


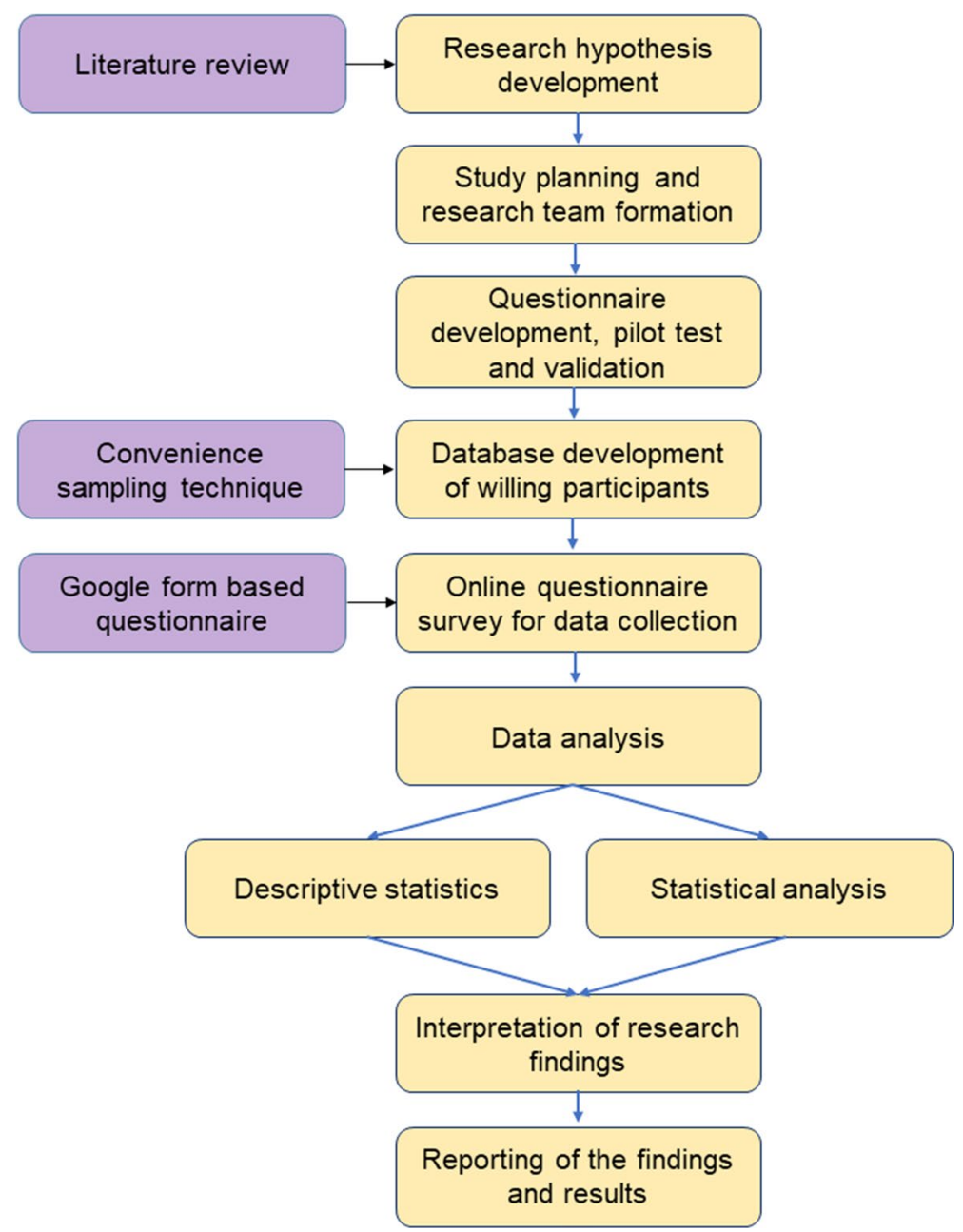

Fig. 2 Flowchart showing the research methodology

questionnaire. This means that the views of people with no access to the internet are not well reflected in the study. Due to these factors, we make no claim that the study is representative of the country's population; nevertheless, the study provides rich insights into WASH and waste disposal practices of the population around the country, as research participants were drawn from most districts in the country. 


\section{Results and discussion}

\subsection{Demographic profile of the participants}

Summary of the demographic characteristics of research participants is presents in Table 1. Among the 1303 research participants who attended the online survey, 57.2\% are male and $42.8 \%$ are female. Most of the participants $(76.34 \%)$ were in the 18-30 age group, while a few $(0.84 \%)$ were above 60 years. Additionally, $14.67 \%$ of participants were aged $31-40$ and $6.39 \%$ were in the $41-50$ age ranges. Finally, $1.76 \%$ were in the 51-60 category. The average age of the research participants was 27.16 years $(\mathrm{SD} \pm 7.78)$. The decision to conduct an online survey accounts for the high proportion of those in the 18-30 age ranges. People in this category tend to be tech savvy and are regular users of internet services (Mamun and Griffiths 2019). Regarding the respondent's educational status, most of the participants attended this survey are found educated and level of education was primary $(1.30 \%)$, secondary $(3.83 \%)$, higher secondary $(24.40 \%)$, graduate $(48.52 \%)$, postgraduate $(19.41 \%)$, and $\mathrm{PhD}(0.70 \%)$, and $1.84 \%$ people have no formal education. From a professional perspective, most of the participants were students (63.90\%), although teacher $(3.20 \%)$, service holder $(16.80 \%)$, businessman $(2.30 \%)$, housewife $(3.70 \%)$, unemployed $(5.60 \%)$, and others $(4.50 \%)$ professional groups were participated in the study. It is found that, among the participants, almost $72 \%$ live in urban or semi-urban, and $28 \%$ in rural area, and among the total 64 administrative districts of the country, participants from 58 districts were attended in this survey. In addition, 50 respondents $(74 \%$ male and $26 \%$ female) participated in a face-to-face informal interview with the mean age of 38.21 years $(\mathrm{SD} \pm 6.18)$. It is found that most of the participants $(60 \%)$ have no formal education, $28 \%$ passed the primary level. and $12 \%$ went to secondary school. Most of them live in the poor urban and semi-urban area or in slum and work as a rickshaw puller, hawker, day labourer, and cleaner and engaged in other professions.

\subsection{Infection prevention and control measures of COVID-19}

As a non-pharmaceutical preventive measures and people's response against COVID-19 water, sanitation and hygienic (WASH) practices, usage and safe disposal of safety equipment was investigated in this study. Most of the participants (89.80\%) mentioned that they were aware of measures to prevent and control the transmission and spread of COVID19 , while $10.20 \%$ were unaware of measures to limit its spread. Facebook and other social media platforms were mentioned by most research participants $(61 \%)$ as their source of information (Fig. 3a). Moreover, radio and television (24.30\%), newspapers (6.30\%), friends and relatives $(3.80 \%)$, and others sources $(5.0 \%)$ were the other channels through which research participants gained information regarding COVID-19, including measures to limit its spread. The finding that most research participants get information from Facebook and other social media platforms corroborates studies which show that social media platforms are increasingly becoming the primary sources of news (Bridgman et al. 2020). But, sometimes consumption of information from social media platforms boosts misperceptions (Donovan 2020). In fact, a recent study highlights a significant difference in the behaviours and attitudes of people who get their news from social media versus news media, even after taking into consideration demographics and factors like scientific literacy and socio-economic differences (Bridgman et al. 2020). The authors note that exposure to 
(a)

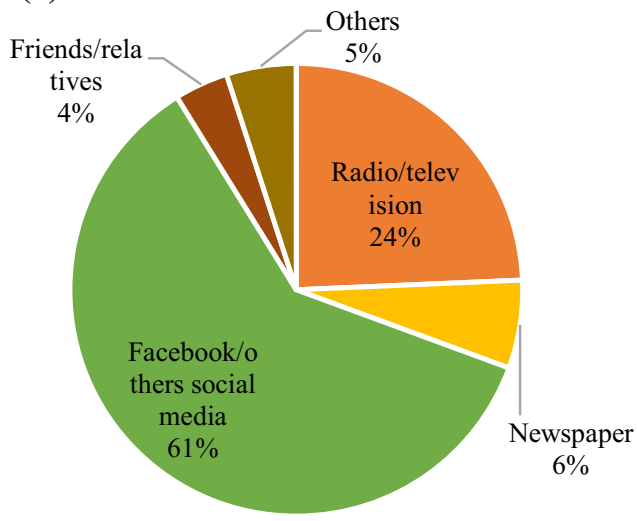

(c)

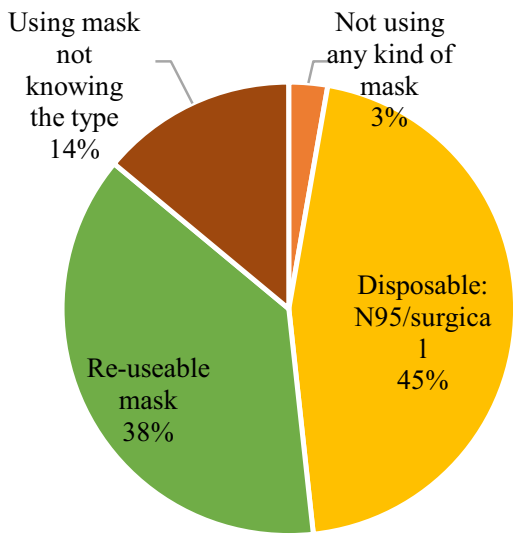

(b)

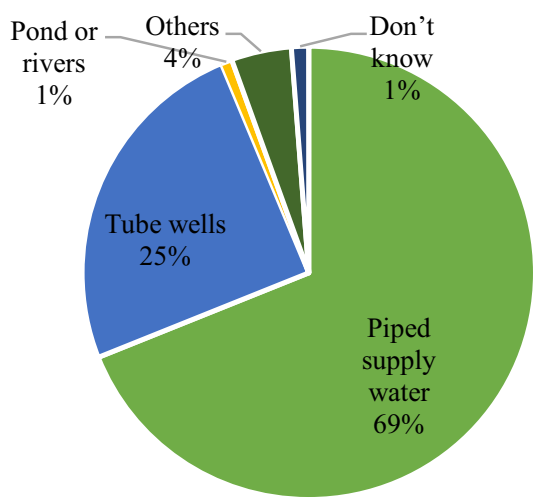

(d)

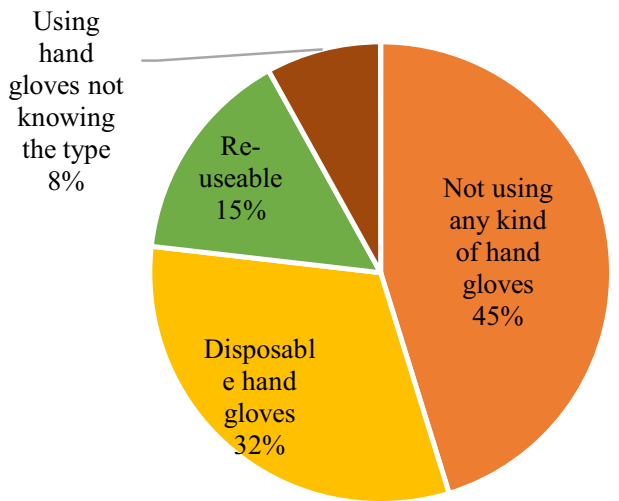

Fig. 3 Respondent's perception regarding a COVID-19-related information and their sources $\mathbf{b}$ sources of potable water supply $\mathbf{c}$ category of used mask and $\mathbf{d}$ hand gloves

misinformation on social media platforms generates misperceptions concerning COVID19 , and misperceptions are linked with lower compliance with preventive actions of disease control (e.g., mask and gloves use, social distancing protocols etc.). Beyond the sources of information, as discussed in the following subsection, WASH practices play a crucial role in the prevention and control of COVID-19 spread.

\subsubsection{Water, sanitation and hygienic (WASH) practices}

Adequate WASH practices are crucial to protect human health during any infectious disease outbreaks, including the COVID-19 (Chand et al. 2020; Das et al. 2020b; Mushi and Shao 2020). Ensuring good and consistently applied WASH practices in communities, homes, schools, marketplaces, and health care facilities will help to prevent humanto-human transmission of the COVID-19 (WHO 2020d). However, adequate safe water is essential for maintaining household activities (Islam 2014; Bodrud-Doza et al. 2019a), and health care purpose. Hence, strengthening water security is necessary for preventing and 
combatting the pandemic situation for drinking, handwashing, maintaining good hygiene, cleaning, and self-isolating (Cooper 2020). According to our findings, it is found that most of the participants $(94.60 \%)$ have available potable water to maintain their daily needs and personal hygiene (S1), with mean value of 4.56 in scale of 1-5 (1 denotes highly disagree to 5 highly agree) (Table 2). The water sources used by research participants were piped supply water $(68.90 \%)$, tube-wells $(24.80 \%)$, pond or rivers $(0.80 \%)$, and others sources (e.g., rainwater) $(4.30 \%)$. A small proportion of research participants (1.20\%) had no knowledge about the sources of water used in their households (Fig. 3b). The fact that most people have access to water is a good starting point, as it facilitates the implementation of other hygienic practices. It is meaningless to call on people to wash their hands on a regular basis if they do not have access to water in the first place.

Moreover, the mean value of the WASH-related statements (i.e., S2-S5 and S8) ranging from 3.58 to 4.67 indicates the people's willingness with the statements (Table 2). Handwashing is a common and essential hygienic practice to protect from infectious pathogens (Brauer et al. 2020; Mushi and Shao 2020), as transmission is usually strengthened by the physical contact between humans (Nicolaides et al. 2020). Evidently, practicing hygiene in the home and everyday life contexts is vital to reducing the burden of infectious diseases, including COVID-19 (Lai and Kaur 2020). Over 95\% of research participants self-reported that they washed their hands with soap, especially before meals and after using the toilet. Beyond handwashing, a healthy household environment is very important regarding the spread of virus and infectious pathogens (Gupta et al. 2019; Gerrard 2020). Based on our findings, $79.80 \%$ of the research participants used antiseptics and disinfectants for house cleaning. This finding is valuable at present due to the current pandemic. Studies show that the use of antiseptics and disinfectants for house cleaning constitutes part of viral infection prevention practices (CDC 2020; Biswal et al. 2020). Moreover, a healthy household environment is associated with access to improved sanitation facilities. About $99 \%$ of the research participants self-reported having improved toilet facilities, and $16 \%$ had more than one toilet in their home. Access to improved sanitation facilities is vital to health in general and in preventing the spread of viruses (Akpakli et al. 2018).

Furthermore, around $64.20 \%$ of the research participants mentioned that they were required to leave their homes for work or to get provisions for their households. While out of their homes for work or other errands, their clothes or shoes may be exposed to the virus (Van-Doremalen et al. 2020). To avoid the infection, it is suggested that take off the wears upon return home, put them in a safe location where they cannot potentially contaminate other things, and wash them (DGHS 2020). In our study, $81.90 \%$ of the research participants indicated that they washed their clothes and outerwear, and cleaned their shoes upon return home. Notably, $18.20 \%$ of the research participants were not aware that they should wash their clothes and outerwear upon returning home if they suspect that they have come in contact with the virus. In addition, $37.80 \%$ of research participants declared using reusable masks, and $64 \%$ of people in this category noted that they washed and sun-dried re-usable masks and gloves before re-use; however, it is alarming that $36 \%$ of research participants were not aware of the necessity to wash reusable masks, especially if they suspect that they may have come in contact with the virus.

We previously mentioned that, to understand the WASH practices of the people at the margin of society who are extremely poor, do not have access to internet services, have limited or no formal education, and live in slums (who couldn't reach via online), we administrated an informal interview. Here, we shed light on WASH practices of this segment of the population. The respondents claimed to have access to potable water, but it was limited with time, as most of them live in slum area, where access to safe water, sanitation, 


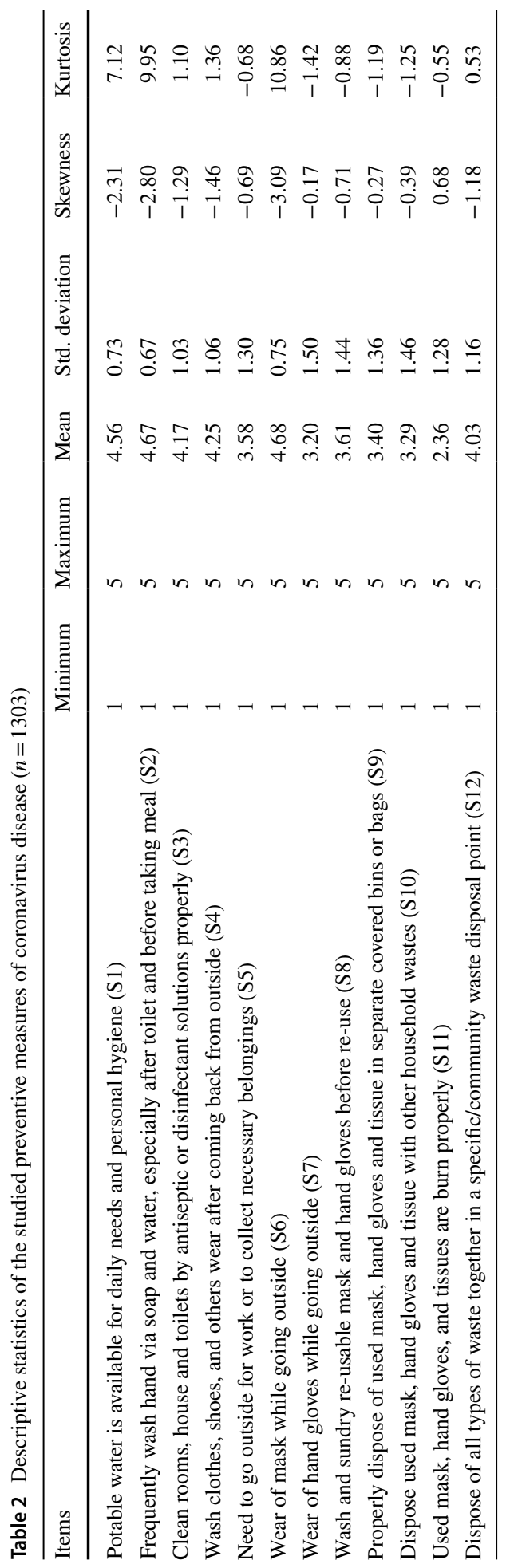


basic health care facilities and other public services are inadequate (Razzak et al. 2014; Islam et al. 2015; Uddin et al. 2015). For some slum residents, the lockdown impacted access to clean water, which leaves them exposed to other infectious diseases. However, almost $98 \%$ of participants in this category are aware of COVID-19, but over $50 \%$ of them did not wash their hands with soap or use a hand sanitizer. In addition, just $38 \%$ have toilets in their households while $62 \%$ use community toilets. Community toilets are often unhygienic, lack functioning water and ventilation systems, and are not disinfected properly (Hanchett et al. 2003; Uddin et al. 2015). The use of community toilets often compromises compliance with social distancing protocol (Das et al. 2020c).

\subsubsection{Usage and disposal of masks and gloves}

To manage daily needs and livelihood purpose, it is necessary to go outside of the house and communicate with others. Hence, people are advised to use protective equipment (e.g., face masks, gloves etc.) to protect against COVID-19 infection (Cook 2020; Islam et al. 2020b; Singh et al. 2020). It is found that most of the participants (94.50\%) wear mask, while going outside, which easily understandable from the mean value of S6 (4.68) (Table 2). Till a small proportion of people in our sample did not use masks (3\%), and $2.8 \%$ of people are not willing to make comments. People who do not wear masks may be doing so due to lack of awareness about COVID-19 with respect to the modes of transmission, or they may find masks unaffordable. Based on the previous point regarding the role of social media, the behaviour of these research participants may also be attributed to misinformation regarding COVID-19 on social media. For research participants who selfreported using masks, $45.50 \%$ noted that they used disposable masks (either surgical or $\mathrm{N}-95$ ) and $37.80 \%$ used cloth (re-usable) face masks (Fig. 3c).

The hands are a very essential part of the human body for more frequent activities like eating, driving, touching, and being involved in many activities. They are also known to facilitate the transmission of virus or pathogens to the human body via touching of the mouth, nose, and eyes or when eating (Beamer et al. 2015). To protect from virus transmission, experts suggest to use hand gloves while touching any objects outside, and not to touch nose, eyes, mouth, face, or any body parts with unwashed hands (Benning et al. 2020; Sajed and Amgain 2020). In our study, hand gloves used behaviour (S7) is not found frequent as like as mask, which evident from the mean value of S7 (3.20) (Table 2). It is found that $54.80 \%$ of participants used gloves, where $31.20 \%$ of people used disposable gloves, $15.10 \%$ used re-useable gloves, and $8.10 \%$ were not aware of the type of gloves they were using (Fig. 3d). A significant proportion (45.20\%) of our research participants did not use gloves.

Like wearing a mask and gloves, proper disposal of these used protective equipment is equally important to tackle the spread of the virus and environmental perspective (Islam et al. 2020b; Rume and Islam 2020; Singh et al. 2020). It is suggested that used masks, gloves and other infectious wastes should be separately disposed of to reduce the spread of virus and other infectious pathogens (DGHS 2020; Ma et al. 2020). The mean value of the statements related to waste disposal issues is found 3.40 (S9) and 3.29 (S10), indicating not very loyal with the statement (Table 2). Less than half $(49.35 \%$ ) of the participants are reported to properly dispose of used mask, gloves, and tissue in a separate covered bins or bags. Over $50 \%$ of people keep them with other household wastes at home, which is an alarming issue. This suggests a lack of awareness regarding how to properly dispose of the infectious healthcare waste. Improper disposal of face masks and gloves is not limited 
to urban residents only. Due to lack of proper waste management channel and authority, rural residents dump all of their household wastes, including infectious waste, in an area nearby the house. In that case, burn of these infectious wastes is better suggested (DGHS 2020). The mean value of S11 is 2.36 (Table 2) indicates the respondent's unwillingness with the statement related to the burning of such wastes. Furthermore, the mean value of $\mathrm{S} 12$ is 4.03 , demonstrating that people agree with the statement (Table 2). It is reported that almost $75.60 \%$ of people disposing of all types of waste together in a specific area or a community waste disposal point, which may create the health hazard of waste workers. Infectious pathogens may easily infect waste collectors in the country, as they are often not well equipped to handle hazardous waste and do not always follow safety protocols (Islam et al. 2016; Rifat et al. 2018; Alam and Qiao 2020).

In the case of the protective equipment use and disposal behaviour of marginal people, $55 \%$ of participants in this category used face masks, usually cloth face masks (re-usable), and none uses gloves. Cloth face masks were washed once or twice a week, which means that people often reused their masks for several days without washing them. It is recommended that cloth masks be washed frequently based on how often they are used (CDC 2020). Doing so is important as the mask touches the nose and mouth, and hence viral particles on it could get into the respiratory system, resulting in an infection. These category of participants is already being highly affected by COVID-19 response measures such as self-isolation and lockdowns. These measures, coupled with the poor state of the economy, have pushed these people into economic despair and have accelerated the consumption of less-nutritious diets. Nutrient-rich diet contributes to strengthening the immune system, which is crucial in fighting diseases such as COVID-19 (Ambuko 2020; Das et al. 2020a). Furthermore, when we explored the waste disposal practices, they reported to keep all the wastes together in a bin or plastic bags. Though, most of the respondents use re-usable mask; disposable mask, tissues and other bio-hazard wastes they dump together with household wastes, which increase the risk of further transition of the COVID-19 infection. They claimed not to know about the safe and separate disposal of wastes. Overall, WASH and waste disposal practice of the respondents is found poor, and the factors that shape these practices are focus in the next section.

\subsection{Factors affecting WASH and waste disposal practices}

Several statistical analyses were performed to explore the factors which influence WASH and waste disposal practices of the population. $T$ test and one-way ANOVA were employed to determine the relationship between demographic characteristics and WASH and waste disposal practices. Based on the results of the $T$-test, variables such as occupation, age, gender, area of residence, and educational level have a significant influence on the studied behaviour or practices (Supplementary Table S1). The one-way ANOVA was also performed to evaluate the relationship between studied factors or statements, and demographic elements (Supplementary Table S2). Based on the one-way ANOVA's result, participant's age is a dependent variable with respect to statements S4 and S5. Usually, the family head and others who provide the needs of the household leave their homes for work and to meet other household needs. Research participants in this category are used to washing their clothes and outerwear, as well as cleaning their shoes upon returning home. Again, the gender difference of the respondents is found significant and dependent on the statements S3, S9, and S12, which are linked with the cleaning and waste disposal issues. Area of residence also influences the participant's WASH and waste disposal practices. More precisely, 
the WASH and waste disposal practices of research participants are shaped by whether they reside in urban or rural areas. In our study, statements S1-S4, S6-S7, and S9-12 are significant and depend on the research participant's area of residence. In Bangladesh, people with higher levels of education and higher income tend to live in urban areas. This segment of the population tends to be aware of health protocols and measures to prevent COVID-19 spread (Samad 2009; BNHBS 2014). Clearly, there are variations in WASH and waste disposal practices, based on whether people reside in urban or rural areas. Level of education and occupation are other factors which influence people's WASH and waste disposal practices. According to our results, the level of education is significant and a dependent variable as it concerns statements $\mathrm{S} 2, \mathrm{~S} 4, \mathrm{~S} 8$, and $\mathrm{S} 9$, which are related to handwashing, cleaning of clothes, and safe disposal of mask and gloves. Also, statements S5-S8 are dependent on the occupation of the research participants, which mainly affects the frequency of leaving home and the use of protective equipment i.e., face mask and gloves.

Principal component analysis (PCA) was further applied in this study to examine the interface between the respondent's perception and factors associated with WASH and waste disposal practices. Table 3 shows the calculated factor loadings together with the cumulative percentage and percentages of variance. From PCA, a total of 5 factors or principal components (PCs) were extracted, which represents $63.831 \%$ of the total variance. The scree plot is used to identify the number of PCs to be retained to insert into the underlying variables (Fig. 4a), while the plot of rotation matrix exhibits a significant association between the studied variables (Fig. 4b). In this study, PC1, PC2, PC3, PC4, and PC5 elucidate the total variance of $20.938,14.666,10.577,8.848$, and $8.802 \%$, respectively. Based on our results, the first principal component (PC1) elucidated $20.938 \%$ of the total variance and encompasses a significant level of positive loading with availability of potable water (S1: 0.745), hand hygiene (S2: 0.779), and face mask use (S6: 0.728). It is also moderately loaded with household hygiene (S3: 0.515) and clothes (S4: 0.549) (Table 3), in accordance with Wang et al.'s (2017) classification of loading score of PCA. PC2 in the datasets explained $14.666 \%$ of total variance, and was positively loaded with safety practices such as use of gloves (S7: 0.612) and corresponding disposal issues such as use of separate

Table 3 Varimax rotated principal component analysis of the studied factors

\begin{tabular}{lrrrrr}
\hline Statements & PC1 & \multicolumn{1}{l}{ PC2 } & \multicolumn{1}{l}{ PC3 } & \multicolumn{1}{l}{ PC4 } & \multicolumn{1}{l}{ PC5 } \\
\hline S1 & 0.745 & -0.119 & 0.019 & 0.037 & -0.155 \\
S2 & 0.779 & 0.207 & 0.11 & -0.006 & 0.156 \\
S3 & 0.515 & 0.487 & 0.187 & -0.165 & 0.114 \\
S4 & 0.549 & 0.446 & 0.103 & -0.171 & 0.173 \\
S5 & 0.079 & -0.05 & 0.058 & 0.944 & 0.037 \\
S6 & 0.728 & 0.182 & 0.001 & 0.186 & 0.182 \\
S7 & 0.144 & 0.612 & 0.096 & 0.005 & 0.05 \\
S8 & 0.117 & 0.003 & 0.016 & 0.038 & 0.959 \\
S9 & 0.236 & 0.524 & 0.228 & -0.095 & 0.016 \\
S10 & -0.098 & 0.051 & 0.858 & 0.187 & 0.015 \\
S11 & -0.108 & 0.755 & -0.164 & 0.046 & -0.081 \\
S12 & 0.371 & 0.096 & 0.619 & -0.175 & 0.013 \\
Eigenvalues & 2.513 & 1.76 & 1.269 & 1.062 & 1.056 \\
\% of Variance & 20.938 & 14.666 & 10.577 & 8.848 & 8.802 \\
Cumulative \% & 20.938 & 35.604 & 46.181 & 55.029 & 63.831 \\
\hline
\end{tabular}


(a) Scree Plot

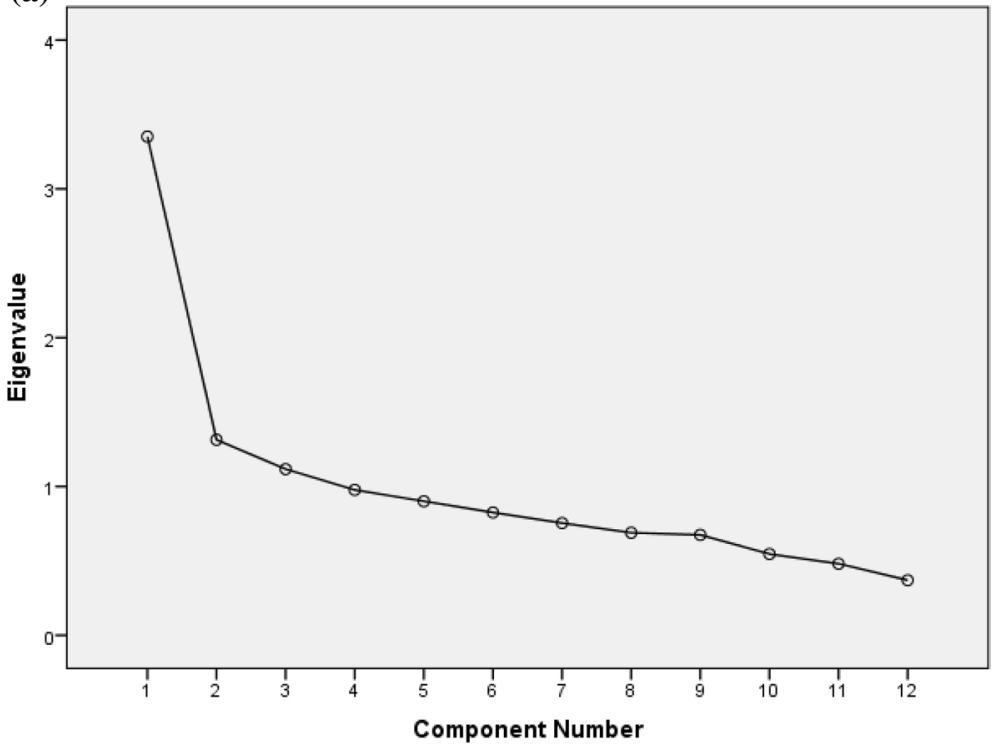

(b) Component Plot in Rotated Space

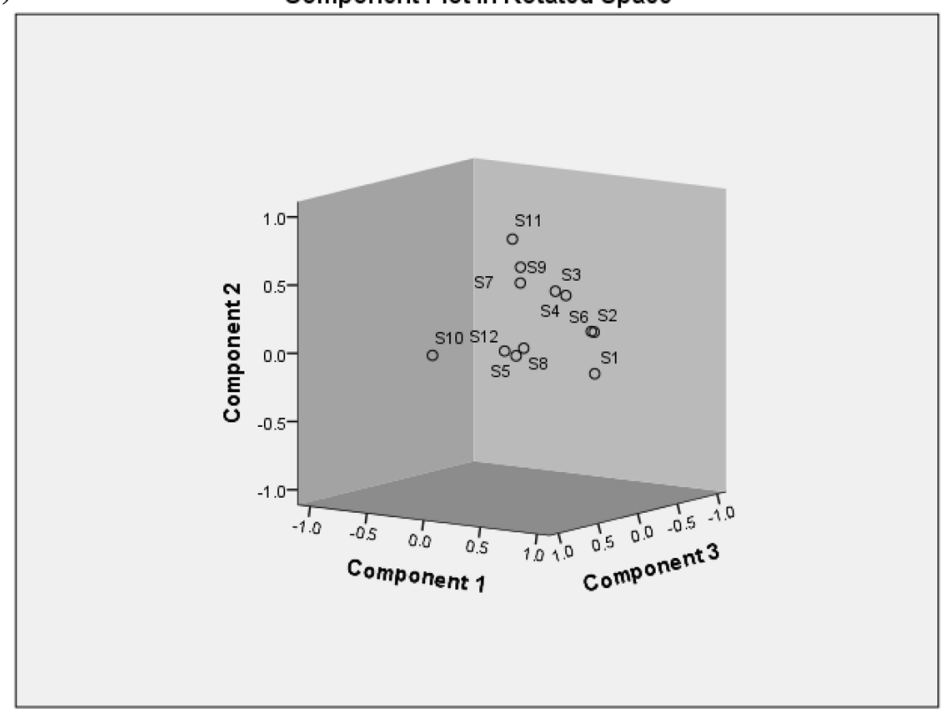

Fig. 4 Principal component analysis by a scree plot of the characteristic roots, and $\mathbf{b}$ component plot in rotated space

bins (S9: 0.524), and burning of infectious waste (S11: 0.755) (Table 3). PC3 elucidated $10.577 \%$ of the total variance, with positive loading of disposal of used masks, gloves, and tissues (medical waste) with household waste into the same bins at home (S10: 0.858), and also in the same community container or waste disposal point (S12: 0.619) (Table 3). People have to leave their homes for work or to meet household needs, so this is included in PC4, with the total variance of 8.848 and loading score S5: 0.944 (Table 3). Finally, PC5 
elucidated $8.802 \%$ of the total variance with strongly positive loading of re-usable face masks and gloves use issues (S8: 0.959) (Table 3). In sum, WASH and waste disposal practices are influenced by the participant's occupation, education level, area of residence and socio-economic structure of the country.

\subsection{Environmental and health perspective}

Poor WASH and waste management practices create environmental degradation (Fig. 5), which poses negative impacts on human health and environment in the long-run. Due to the lack of proper sanitation and treatment of municipal wastewater, viral infection can spread to the surrounding life and environment. Recently, SARS-CoV-2 virus was excreted in COVID-19 patients' faeces, and also from municipal wastewater of many countries like Australia, India, Sweden, and USA (Ahmed et al. 2020; Rume and Islam 2020). So, proper treatment of municipal wastewater and additional measures is essential to reduce the further disease transmission. But, it would be challenging for developing countries like Bangladesh, where municipal wastewater is usually drained into nearby aquatic bodies and rivers without treatment (Islam and Azam 2015; Rahman and Islam 2016).

Moreover, the increase in waste load and their haphazard disposal also create environmental burden. During the pandemic, online shopping and home delivery got popularity in many countries including Bangladesh, which ultimately increase the amount of household wastes (Somani et al. 2020; Rume and Islam 2020). To protect from viral infection, mass people are now using masks, hand gloves and other protective equipment's in domestic level, which also increases the amount of hazardous healthcare wastes. Due to the lack of proper disposal, these wastes create environmental burden like clogging in water ways, generating microplastic fibres, and contaminate soil and water environment (Fadare and Okoffo 2020; Islam et al. 2020b; Sarkodie and Owusu 2020). Though experts and responsible authorities suggest proper disposal and segregation of household organic waste with plastic-based protective equipment, mixed up of these wastes increase the risk of disease transmission and exposure to the virus of waste workers (Ma et al. 2020; Rahman et al. 2020; Somani et al. 2020). Based on estimates, there are 40,000 informal waste collectors across the country, most of whom handle waste without following health and safety protocols (Alam and Qiao 2020). Poor management of the COVID-19 wastes in Bangladesh,

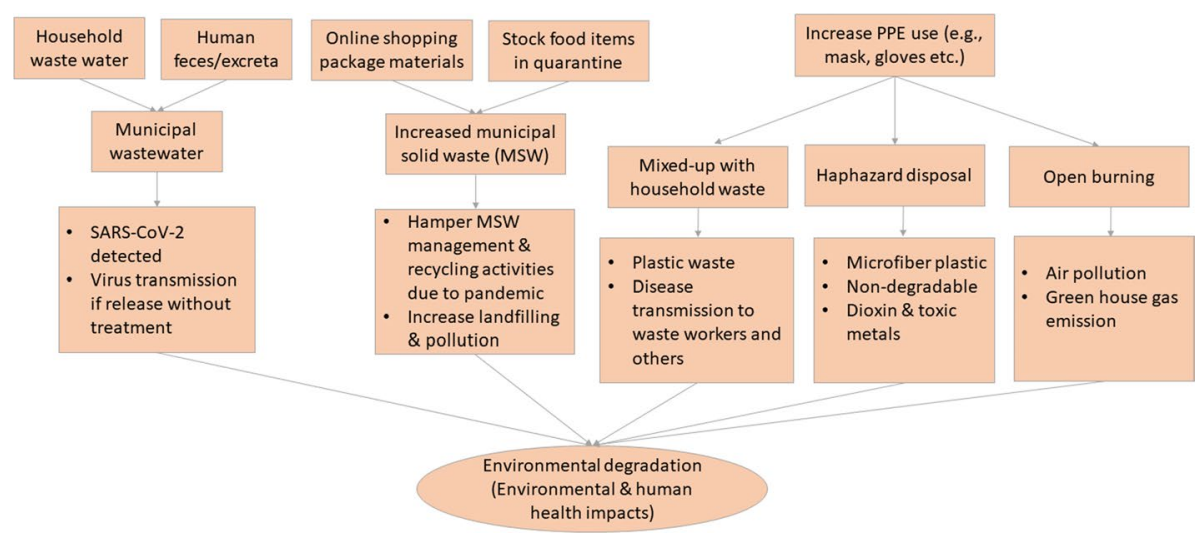

Fig. 5 Diagram showing the environmental and health perspective of WASH and waste disposal practices 
increasing infection risks and environmental hazards in highly infected areas like Dhaka and other cities across the country. Moreover, polypropylene is the common material of protective equipment like N-95 masks, and Tyvek are protective suits, hand gloves, and medical face shields, which can persist for a long time and pollute the environment (Singh et al. 2020). Due to the disruption of routine municipal waste management and plastic waste recovery and recycling activities for the pandemic, it increases the landfilling and environmental pollutants like dioxins and toxic metals (Singh et al. 2020; Somani et al. 2020). Overall, it can be said that, due to haphazard disposal and improper management of waste, the environment as well as human health is at high risk of disease transmission in future.

\section{Conclusions}

In the absence of a proven vaccine or medicine, various measures have been adopted to prevent and control the transmission and spread of COVID-19. Upholding best WASH and waste disposal practices in the home and community is important for preventing the spread of COVID-19, so the aim of this paper was to examine WASH and waste disposal practices of the population. Our findings show that most people are aware of measures to prevent and control the transmission and spread of COVID-19. Facebook and other social media platforms are the principal channels through which people get information regarding COVID19. This is problematic as these platforms also serve as channels used to spread messages which are misleading or based on junk science. According to our findings, most of the participants wear face mask in public places and wash their hands using soap. Factors such as occupation, area of residence, and level of education influence WASH and waste disposal practices of the participants. For instance, among those with little or no formal education, over $50 \%$ did not wash their hands with soap. Urban residents are more inclined to follow measures aimed at preventing the spread of COVID-19, such as wearing a mask in public places and washing clothes upon return home. But, the waste disposal practices are found inappropriate, and most of the respondents disposed of used mask, gloves, and others infectious wastes with household wastes instead of separate disposal. Therefore, it is essential to increase the awareness level of mass people regarding the preventive measures of COVID19 , along with the importance of WASH and safe infectious waste disposal practices.

Moreover, time-oriented policy should be introduced and implement to control the further spread of COVID-19 and save the environment. Regarding the finding, most people don't get information of COVID-19 including preventive measures, hence necessitates reconsidering modes of diffusing vital information. In addition to reaching the population via traditional channels such as radio and television, the government could also use social media platforms to reach a wide audience. Regarding messaging, the government should avoid COVID-19 messages that are unclear and contradictory. Also, limiting the spread of infectious diseases requires tackling inequality in society. A resilient society is one which also confronts inequality. Finally, there is a need for WASH interventions in slums, as doing so could contribute towards preventing and controlling the spread of the virus. For example, the government could provide handwashing stations. Also, the government could distribute soap to populations in slums or poor areas who find it unaffordable. An increase in handwashing in vulnerable communities would contribute to preventing and controlling the spread of COVID-19. The critical role of adequate WASH and waste disposal practices in the context of the current pandemic cannot be overemphasized. 
Acknowledgements The authors would like to gratitude the participants of the survey for their valuable response. Besides, the Centre for Health Innovation, Networking, Training, Action and Research-Bangladesh (which was previously known as the Undergraduate Research Organization), volunteers are highly appreciated for their efforts in circulating the survey link to the eligible respondents.

Funding This study did not receive any specific grant from funding agencies in the public, commercial, or not-for-profit sectors.

\section{Compliance with ethical standards}

Conflict of interest The authors declare no conflict of interest.

Ethical approval Participants were informed the purpose of the study, and have taken their consent before enrolling in the survey and remained anonymous. The survey was completed only once, and the survey could be completed/terminated whenever they wished. The survey content and procedure were reviewed and approved by the Institute of Allergy and Clinical Immunology of Bangladesh (IACIB), Savar, Dhaka.

\section{References}

Ahmed, W., Angel, N., Edson, J., Bibby, K., Bivins, A., O’Brier, J. W., et al. (2020). First confirmed detection of SARS-CoV-2 in untreated wastewater in Australia: A proof of concept for the wastewater surveillance of COVID-19 in the community. Science of the Total Environment, 728, 138764. https://doi. org/10.1016/j.scitotenv.2020.138764.

Akpakli, D., Manyeh, A., Akpakli, J., Kukula, V., \& Gyapong, M. (2018). Determinants of access to improved sanitation facilities in rural districts of southern Ghana: Evidence from Dodowa health and demographic surveillance site. BMC Research Notes. https://doi.org/10.1186/s13104-018-3572-6.

Alam, O., \& Qiao, X. (2020). An in-depth review on municipal solid waste management, treatment and disposal in Bangladesh. Sustain Cities Society, 52, 101775. https://doi.org/10.1016/j.scs.2019.101775.

Ambuko J (2020) Eating healthy to boost our immunity and protect our bodies from disease-causing infections including COVID-19. https://uonresearch.org/blog/eating-healthy-to-boost-our-immunity-andprotect-our-bodies-from-disease-causing-infections-including-covid-19/ (assessed July 07, 2020)

Anderson, E. L., Turnham, P., Griffin, J. R., \& Clarke, C. C. (2020). Consideration of the aerosol transmission for COVID-19 and public health. Risk Analysis, 40(5), 902-907.

Anwar, S., Nasrullah, M., \& Hosen, M. J. (2020). COVID-19 and Bangladesh: Challenges and how to address them. Frontiers in Public Health. https://doi.org/10.3389/fpubh.2020.00154.

Beamer, P. I., Plotkin, K. R., Gerba, C. P., Sifuentes, L. Y., Koenig, D. W., \& Reynolds, K. A. (2015). Modeling of human viruses on hands and risk of infection in an office workplace using micro-activity data. Journal of Occupational and Environmental Hygiene, 12(4), 266-275.

Benning SD, Labus B, and Barchar K.A (2020) To fight coronavirus, here's a trick to stop touching your face so often. https://www.marketwatch.com/story/to-fight-coronavirus-heres-how-you-truly-can-stoptouching-your-face-so-often-2020-03-23 (assessed 06 July 2020)

Biswal, M., Kanaujia, R., Angrup, A., \& Ray, P. (2020). Disinfection tunnels: Potentially counterproductive in the context of a prolonged pandemic of COVID-19. Public Health, 183, 48-49.

BNHBS (2014) Bangladesh national hygiene baseline survey: preliminary report, https://www.ircwash.org/ resources/bangladesh-national-hygiene-baseline-survey-preliminary-report (assessed 05 July 05 2020)

Bodrud-Doza, M., Bhuiyan, M. A. H., Islam, S. M. D., Rahman, M. S., Haque, M. M., Fatema, K. J., et al. (2019a). Hydrogeochemical investigation of groundwater in Dhaka city of Bangladesh using GIS and multivariate statistical techniques. Groundwater for Sustainable Development, 8, 226-244.

Bodrud-Doza, M., Islam, S. M. D., Hasan, M. T., Alam, F., Haque, M. M., Rakib, M. A., et al. (2019). Groundwater pollution by trace metals and human health risk assessment in central west part of Bangladesh. Groundwater for Sustainable Development, 9, 100219. https://doi.org/10.1016/j. gsd.2019.100219.

Bodrud-Doza, M., Islam, S. M. D., Rume, T., Quraishi, S. B., Rahman, M. S., \& Bhuiyan, M. A. H. (2020). Groundwater quality and human health risk assessment for safe and sustainable water supply of Dhaka city dwellers in Bangladesh. Groundwater for Sustainable Development, 10, e100374. https://doi. org/10.1016/j.gsd.2020.100374. 
Bodrud-Doza, M., Shammi, M., Bahlman, L., Islam, A. R. M. T., \& Rahman, M. M. (2020). Psychosocial and socio-economic crisis in Bangladesh due to COVID-19 pandemic: A perception-based assessment. Frontiers in Public Health. https://doi.org/10.3389/fpubh.2020.00341.

Brauer, M., Zhao, J. T., Bennitt, F. B., \& Stanaway, J. D. (2020). Global access to handwashing: implications for COVID-19 control in low-income countries. Environmental Health Perspectives. https://doi. org/10.1289/EHP7200.

Bridgman, A., Merkley, E., Loewen, P. J., Owen, T., Ruths, D., Teichmann, L., \& Zhilin, O. (2020). The causes and consequences of COVID-19 misperceptions: Understanding the role of news and social media. The Harvard Kennedy School (HKS) Misinformation Review. https://doi.org/10.37016/ mr-2020-028.

Centers for disease control and prevention (CDC) (2020) Cleaning and disinfecting your home. https://www. cdc.gov/coronavirus/2019-ncov/prevent-getting-sick/disinfecting-your-home.html (assessed 05 July 2020)

Chand, S., Shastry, C. S., Hiremath, S., Joel, J. J., Bhat, C. H. K., \& Mateti, U. V. (2020). Water, sanitation, hygiene and biomedical waste disposal in the healthcare system: A review. Biomedicine, 40(1), 14-19.

Chen, X., Ran, L., Liu, Q., Hu, Q., Du, X., \& Tan, X. (2020). Hand hygiene, mask-wearing behaviors and its associated factors during the COVID-19 epidemic: A cross-sectional study among primary school students in Wuhan, China. International Journal of Environmental Research and Public Health, 17, 2893. https://doi.org/10.3390/ijerph17082893.

Cook, T. M. (2020). Personal protective equipment during the COVID-19 pandemic-A narrative review. Anaesthesia, 75, 920-927.

Cooper R (2020) Water security beyond Covid-19. K4D Helpdesk Report 803. Brighton, UK: Institute of Development Studies. https://opendocs.ids.ac.uk/opendocs/handle/20.500.12413/15240

Corburn, J., Vlahov, D., Mberu, B., Riley, L., Caiffra, W., Rashid, S., et al. (2020). Slum health: Arresting COVID-19 \& improving well-being in urban informal settlements. Journal of Urban Health, 97, 348-357.

Corner, R. J., \& Dewan, A. M. (2014). Dhaka megacity: Geospatial perspectives on urbanization, environment and health. Netherlands: Springer.

Das, A., Das, M., \& Ghosh, S. (2020). Impact of nutritional status and anemia on COVID-19: Is it a public health concern? Evidence from national family health survey-4 (2015-2016) India. Public Health, 185, 93. https://doi.org/10.1016/j.puhe.2020.06.001.

Das, A., Ghosh, S., Das, K., Basu, T., Das, M., \& Dutta, I. (2020). Modelling the effect of area-deprivation on COVID-19 incidences: A study of Chennai megacity, India. Public Health, 185, 266-269.

Das, A., Ghosh, S., Das, K., Dutta, I., Basu, T., \& Das, M. (2020). (In) visible impact of inadequate WaSH Provision on COVID-19 incidences can be not be ignored in large and megacities of India. Public Health. https://doi.org/10.1016/j.puhe.2020.05.035.

Delgado, D., Quintana, F. W., Perez, G., Liprandi, A. S., Ponte-Negretti, C., Mendoza, I., \& Baranchuk, A. (2020). Personal safety during the COVID-19 pandemic: Realities and perspectives of healthcare workers in Latin America. International Journal of Environmental Research and Public Health, 17, 2798. https://doi.org/10.3390/ijerph17082798.

DGHS (2020) National guideline on infection prevention and control in healthcare settings with additional measures for covid-19. Directorate General of Health Services, Ministry of Health and family welfare, Government of the people's Republic of Bangladesh, Dhaka. https://drive.google.com/file/d/1gURH _1KzI7Fz1zgzrV4Jg42UDzxE-1y/view (assessed 26 October 2020)

Donovan, J. (2020). Social-media companies must flatten the curve of misinformation. Nature. https://doi. org/10.1038/d41586-020-01107-z.

Fadare, O. O., \& Okoffo, E. D. (2020). Covid-19 face masks: A potential source of microplastic fibers in the environment. Science of the Total Environment, 737, 140279. https://doi.org/10.1016/j.scito tenv.2020.140279.

Gerrard, E. (2020). Infection control and hygiene: A guide to best practice. Veterinary Nursing Journal, $35(2), 38-41$.

Gupta, V., Kumar, R., Sood, U., \& Singhvi, N. (2019). Reconciling hygiene and cleanliness: A new perspective from human microbiome. Indian Journal of Microbiology. https://doi.org/10.1007/s12088-01900839-5.

Hanchett, S., Akhter, S., \& Khan, M. H. (2003). Water, sanitation and hygiene in Bangladeshi slums: An evaluation of the WaterAid- Bangladesh urban programme. Environment and Urbanization, 15(2), 43-56.

Hathi, P., Haque, S., Pant, L., Coffey, D., \& Spears, D. (2017). Place and child health: The interaction of population density and sanitation in developing countries. Demography, 54, 337-360. 
Holshue, M. L. (2020). First case of 2019 novel coronavirus in the United States. New England Journal of Medicine, 382, 929-936.

Howell, C. D. (2002). Statistical methods for psychology (7th ed.). US: University of Vermont.

Huang, C., Wang, Y., Li, X., Ren, L., Zhao, J., Hu, Y., et al. (2020). Clinical features of patients infected with 2019 novel coronavirus in Wuhan, China. The Lancet, 395, 497-506.

IEDCR (2020) Institute of epidemiology, disease control and research. Corona info in Bengali. https:// corona.gov.bd/ (assessed 27 October 2020)

Ilesanmi, O., \& Afolabi, A. (2020). Time to move from vertical to horizontal approach in our COVID-19 response in Nigeria. SciMedicine Journal. https://doi.org/10.28991/SciMedJ-2020-02-SI-3.

Islam, M. S., Anannya, A. M., Rahman, M. S., \& Rahman, M. M. (2015). Present situation of water supply and sanitation at Karail Slum Dhaka. Journal of Environmental Science and Natural Resource, $8(1), 161-163$.

Islam SMD (2013) Evaluation of environmental and socio-economic impact due to cyclone Aila, present condition and adaptation practices in Shyamnagar, Satkhira of Bangladesh. Unpublished Undergraduate Thesis, Department of Environmental Sciences, Jahangirnagar University, Dhaka

Islam SMD (2014) Geoelectrical and hydrogeochemical studies for delineating seawater intrusion in coastal aquifers of Kalapara upazila, Patuakhali, Bangladesh. Unpublished Master's Thesis, Department of Environmental Sciences, Jahangirnagar University, Dhaka

Islam, S. M. D., \& Azam, G. (2015). Seasonal variation of physicochemical and toxic properties in three major rivers; Shitalakhya, Buriganga and Turag around Dhaka city, Bangladesh. Journal of Biodiversity and Environmental Sciences, 7(3), 120-131.

Islam, S. M. D., Bodrud-Doza, M., Khan, R. M., Haque, M. A., \& Mamun, M. A. (2020). Exploring COVID-19 stress and its factors in Bangladesh: A perception-based study. Heliyon, 6(7), e04399. https://doi.org/10.1016/j.heliyon.2020.e04399.

Islam, S. M. D., \& Huda, M. E. (2016). Water pollution by industrial effluent and phytoplankton diversity of Shitalakhya river Bangladesh. Journal of Scientific Research, 8(2), 191-198.

Islam, S. M. D., Rahman, S. H., Hassan, M., \& Azam, G. (2016). Municipal solid waste management using GIS application in Mirpur area of Dhaka city Bangladesh. Pollution, 2(2), 141-151.

Islam, S. M. D., Safiq, M. B., Bodrud-Doza, M., \& Mamun, M. A. (2020). Perception and attitudes towards PPE-related waste disposal amid COVID-19 in Bangladesh: An exploratory study. Frontiers in Public Health. https://doi.org/10.3389/fpubh.2020.592345.

Jefferson, T., Del Mar, C. B., Dooley, L., Ferroni, E., Al-Ansary, L. A., Bawazeer, G., et al. (2009). Physical interventions to interrupt or reduce the spread of respiratory viruses: Systematic review. BMJ, 339, b3675.

Kamruzzaman M (2020) Bangladesh to partly ease lockdown amid virus concerns. https://www.aa.com. tr/en/asia-pacific/bangladesh-to-partly-ease-lockdown-amid-virus-concerns/1855714 (assessed 27 June 2020)

Kaur, S., Bherwani, H., Gulia, S., Vijay, R., \& Kumar, R. (2020). Understanding COVID-19 transmission, health impacts and mitigation: Timely social distancing is the key. Environment Development and Sustainability. https://doi.org/10.1007/s10668-020-00884-x.

Kim, T. K. (2015). T test as a parametric statistic. Korean Journal of Anesthesiology, 68(6), 540-546.

Labrague, L. J., McEnroe-Petitte, D. M., van de Mortel, T., \& Nasirudeen, A. A. (2018). Systematic review on hand hygiene knowledge and compliance in student nurses. International Nursing Review, 65, 336-348.

Lai, Z. F. Y., \& Kaur, S. (2020). Home hygiene and prevention of infections. Asia Pacific Journal of Health Management. https://doi.org/10.24083/apjhm.v15i2.397.

Luby, S. P., Agboatwalla, M., Feikin, D. R., Painter, J., Billhimer, W., Altaf, A., \& Hoekstra, R. M. (2005). Effect of handwashing on child health: A randomised controlled trial. The Lancet, 366, 225-233.

Ma, Y., Lin, X., Wu, A., Huang, Q., Li, X., \& Yan, J. (2020). Suggested guidelines for emergency treatment of medical waste during COVID-19: Chinese experience. Waste Disposal and Sustainable Energy, 2, 81-84.

Mamun, M. A., \& Griffiths, M. D. (2019). The assessment of internet addiction in Bangladesh: Why are prevalence rates so different? Asian Journal of Psychiatry, 40, 46-47.

Mamun, M. A., \& Griffiths, M. D. (2020). First COVID-19 suicide case in Bangladesh due to fear of COVID-19 and xenophobia: Possible suicide prevention strategies. Asian Journal of Psychiatry, 51, e102073.

Mushi, V., \& Shao, M. (2020). Tailoring of the ongoing water, sanitation and hygiene interventions for prevention and control of COVID-19. Tropical Medicine and Health, 48, 47. https://doi. org/10.1186/s41182-020-00236-5. 
Nicolaides, C., Avraam, D., Cueto-Felgueroso, L., Gonzalez, M. C., \& Juanes, R. (2020). Hand-hygiene mitigation strategies against global disease spreading through the air transportation network. Risk Analysis, 40(4), 723-740.

Ojong, N. (2020). The COVID-19 pandemic and the pathology of the economic and political architecture in Cameroon. Healthcare, 8(2), 176. https://doi.org/10.3390/healthcare8020176.

Qian, M., \& Jiang, J. (2020). COVID-19 and social distancing. Journal of Public Health. https://doi. org/10.1007/s10389-020-01321-z.

Rahman, M. M., Bodrud-Doza, M., Griffiths, M. D., \& Mamun, M. A. (2020). Biomedical waste amid COVID-19: Perspectives from Bangladesh. The Lancet Global Health. https://doi.org/10.1016/ S2214-109X(20)30349-1.

Rahman, S. H., \& Islam, S. M. D. (2016). Degrading riverine ecology of Bangladesh and options for management. SUB Journal of Sustainable Environment and Development, 1, 11-27.

Ray, I. (2020). Viewpoint-handwashing and COVID-19: Simple, right there...? World Development, 135, $1-3$.

Razzak, N. R. B., Chowdhury, S., \& Ohi, S. B. (2014). Assessment of essential public services in slums of Dhaka city. Current Advances in Civil Engineering, 2(4), 126-132.

Rifat, M. A., Biswas, A., Sufian, H. B., Azad, F., \& Zahid, M. K. (2018). Socio-economic status, hygiene practices and microbial exposure of the waste collectors of Dhaka city in Bangladesh. Global Journal of Health Science, 10(12), 96-103.

Rothan, H., \& Byrareddy, S. (2020). The epidemiology and pathogenesis of coronavirus disease (COVID-19) outbreak. Journal of Autoimmunity, 109, 1-4.

Rume, T., \& Islam, S. M. D. (2020). Environmental effects of COVID-19 pandemic and potential strategies of sustainability. Heliyon, 6, e04965. https://doi.org/10.1016/j.heliyon.2020.e04965.

Sajed, A. N., \& Amgain, K. (2020). Corona virus disease (COVID-19) outbreak and the strategy for prevention. Europasian Journal of Medical Sciences, 2(1), 1-3. https://doi.org/10.46405/ejms.v2i1.38.

Samad, R. B. (2009). Strengthening financial capability of a municipality: A case study of Dhaka city corporation. Journal of Bangladesh Institute of Planners, 2, 136-144.

Sarkodie, S. A., \& Owusu, P. A. (2020). Impact of COVID-19 pandemic on waste management. Environment Development and Sustainability. https://doi.org/10.1007/s10668-020-00956-y.

Shammi, M., Bodrud-Doza, M., Islam, A. R. M. T., \& Rahman, M. M. (2020). Strategic assessment of COVID-19 pandemic in Bangladesh: Comparative lockdown scenario analysis, public perception, and management for sustainability. Environment Development and Sustainability. https://doi. org/10.1007/s10668-020-00867-y.

Singh, N., Tang, Y., \& Ogunseitan, O. A. (2020). Environmentally sustainable management of used personal protective equipment. Environmental Science and Technology. https://doi.org/10.1021/acs. est.0c03022.

Somani, M., Srivastava, A. N., Gummadivalli, S. K., \& Sharma, A. (2020). Indirect implications of COVID-19 towards sustainable environment: An investigation in Indian context. Bioresource Technology Reports, 11, 100491. https://doi.org/10.1016/j.biteb.2020.100491.

Uddin, A. K. M. M., Haque, M. M., Arafat, Y., Roy, S. K., Khan, M. Z. H., \& Islam, K. (2015). Study on hygiene practice of the adult domestic household women worker in urban slum area of Dhaka city. ChattagramMaa-O-Shishu Hospital Medical College Journal, 14(1), 52-54.

UNDESA. (2018). The World 's Cities in 2018-Data Booklet (ST/ESA/SER.A/417). In United Nations, Department of Economic and Social Affairs (UNDESA), Population Division. https://www.un.org/ en/events/citiesday/assets/pdf/the_worlds_cities_in_2018_data_booklet.pdf (accessed 10 October 2020)

UNDP (2020). Bangladesh: Transforming life in the slums. https://www.undp.org/content/undp/en/ home/ourwork/ourstories/bangladesh--how-to-transform-life-in-the-slum.html (assessed 5 October 2020)

Van-Doremalen, N., Bushmaker, T., Morris, D. H., Holbrook, M. G., Gamble, A., Williamson, B. N., \& Lloyd-Smith, J. O. (2020). Aerosol and surface stability of SARSCoV-2 as compared with SARSCoV-1. New England Journal of Medicine, 382(16), 1564-1567.

Wang, J., Liu, G., Liu, H., \& Lam, P. K. (2017). Multivariate statistical evaluation of dissolved trace elements and a water quality assessment in the middle reaches of Huaihe river, Anhui, China. Science of the Total Environment, 583, 421-431.

WHO (2020a) 2019-nCoV outbreak is an emergency of international concern. http://www.euro.who.int/ en/health-topics/health-emergencies/international-healthregulations/news/news/2020/2/2019-ncovoutbreak-is-an-emergency-of-international-concern (accessed 27 April 2020).

WHO (2020b) Coronavirus disease (COVID-19) pandemic. World Health Organization, Geneva. https:// www.who.int/emergencies/diseases/novel-coronavirus-2019 (assessed 27 October, 2020) 
WHO (2020c) Rational use of personal protective equipment (PPE) for coronavirus disease (COVID-19) https://apps.who.int/iris/bitstream/handle/10665/331498/WHO-2019-nCoV-IPCPPE_use-2020.2-eng. pdf (assessed 2 July 2020)

WHO (2020d) Water, sanitation, hygiene and waste management for the COVID-19 virus. Interim guidance 19 March 2020 https://www.who.int/publications/i/item/water-sanitation-hygiene-and-waste-manag ement-for-the-covid-19-virus-interim-guidance (assessed 13 July 2020)

WHO (2020e) COVID-19 Bangladesh situation reports. Situation report - 35. https://www.who.int/docs/ default-source/searo/bangladesh/covid-19-who-bangladesh-situation-reports/who-covid-19-update-3520201026.pdf?sfvrsn=b1d404af_2 (Assessed 27 October 2020)

World Bank. (2018). Promising progress: A diagnostic of water supply, sanitation, hygiene, and poverty in Bangladesh. Washington, DC: WASH Poverty Diagnostic World Bank.

Yates C, Allen T, Joseph J, Lantagne M (2017) Evidence synthesis humanitarian evidence programme WASH interventions in disease outbreak response. https:// reliefweb.int/sites/reliefweb.int/files/ resources/OX-HEP-WASH-Print.pdf (accessed 11 May 2020)

Zohura, F., Bhuyian, M., Saxton, R., Parvin, T., et al. (2020). Effect of a water, sanitation and hygiene program on handwashing with soap among household members of diarrhoea patients in healthcare facilities in Bangladesh: A cluster-randomised controlled trial of the CHoBI7 mobile health program. Tropical Medicine and International Health, 25(8), 1008-1015.

Publisher's Note Springer Nature remains neutral with regard to jurisdictional claims in published maps and institutional affiliations.

\section{Affiliations}

\section{S. M. Didar-UI Islam ${ }^{1}$ (D) . Prantor Kumar Mondal ${ }^{1} \cdot$ Nathanael Ojong $^{2}$. Md. Bodrud-Doza ${ }^{3}$ D $\cdot$ Md. Abu Bakar Siddique ${ }^{3} \cdot$ Moazzem Hossain $^{4}$. Mohammed A. Mamun ${ }^{5,6}$ (D)}

\section{S. M. Didar-U1 Islam} didar_577@yahoo.com

1 School of Environment, Tsinghua University, Beijing 100084, China

2 International Development Studies, 324 Founders College, York University, 4700 Keele Street, Toronto, Canada

3 Climate Change Programme (CCP), BRAC, 75 Mohakhali, Dhaka 1212, Bangladesh

4 Institute of Allergy and Clinical Immunology of Bangladesh (IACIB), Savar, Dhaka, Bangladesh

5 Centre for Health, Innovation, Networking, Training, Action and Research-Bangladesh, Dhaka, Bangladesh

6 Department of Public Health and Informatics, Jahangirnagar University, Dhaka 1342, Bangladesh 